\title{
Diagnostic yield of endoscopic ultrasonography in patients with intermediate or high likelihood of choledocholithiasis: a retrospective study from one university-based endoscopy center
}

\author{
Varayu Prachayakul ${ }^{1 *}$, Pitulak Aswakul ${ }^{2}$, Patommatat Bhunthumkomol ${ }^{3}$ and Morakod Deesomsak ${ }^{2}$
}

\begin{abstract}
Background: Diagnosis of choledocholithiasis requires clinical manifestations and imaging examination findings suggesting a stone in the common bile duct (CBD), but these factors are not highly sensitive or specific. The choledocholithiasis management algorithm proposed by the American Society for Gastrointestinal Endoscopy (ASGE) may not be appropriate for patients who fulfill the clinical criteria for a high likelihood of choledocholithiasis. Endoscopic ultrasonography (EUS) may replace endoscopic retrograde cholangiopancreatography (ERCP) for the detection of CBD stones in all patients. The aims of this study were to determine the diagnostic yield and optimal timing of EUS in patients with an intermediate or high likelihood of choledocholithiasis requiring therapeutic ERCP.

Methods: Patients with suspected choledocholithiasis who underwent EUS between June 2009 and January 2012 were retrospectively reviewed. The patients were divided into two groups based on the likelihood of choledocholithiasis according to the clinical predictors described by the ASGE guidelines: an intermediate likelihood group and a high likelihood group. The demographic data, clinical manifestations at presentation, blood test results, EUS and ERCP findings, and clinical manifestations during the follow-up period were recorded and analyzed.

Results: Ninety-three patients were enrolled in the study $(52.7 \%$ in the intermediate likelihood group and $47.3 \%$ in the high likelihood group). CBD stones were detected in $22.44 \%$ of patients in the intermediate likelihood group and $38.63 \%$ of patients in the high likelihood group. EUS had a sensitivity of $100 \%$ and specificity of $80 \%$ for detection of CBD stones. An alkaline phosphatase level of $>133 \mathrm{mg} / \mathrm{dL}$ (area under the curve, 0.576 ) was the only factor that was significantly associated with detection of CBD stones in patients who underwent EUS $>7$ days after the initial clinical presentation (odds ratio $4.87, p=0.01$ ).

Conclusions: EUS is an accurate diagnostic tool for the detection of CBD stones, and can prevent the unnecessary use of ERCP. This study found that use of clinical criteria alone might not provide a good prediction of the presence of CBD stones, even in patients who fulfill the criteria for a high likelihood of choledocholithiasis.
\end{abstract}

Keywords: Endoscopic ultrasonography, Choledocholithiasis, Clinical likelihood, High likelihood, Intermediate likelihood

\footnotetext{
* Correspondence: kaiyjr@gmail.com

'Department of Internal Medicine, Siriraj GI Endoscopy Center, Siriraj Hospital, Division of Gastroenterology, Faculty of Medicine, Mahidol University, Bangkok, Thailand

Full list of author information is available at the end of the article
} 


\section{Background}

Choledocholithiasis is a common condition, which occurs in $10-20 \%$ of patients with cholelithiasis, $7-14 \%$ of patients who have undergone cholecystectomy, and 18-33\% of patients with acute biliary pancreatitis [1]. Management of patients with suspected choledocholithiasis requires confirmation of stones in the common bile duct (CBD).

Diagnosis of choledocholithiasis is based on clinical signs and symptoms, levels of serum markers of cholestasis, and imaging examination findings (transabdominal ultrasonography), but these factors are not highly sensitive or specific. Endoscopic retrograde cholangiopancreatography (ERCP) is the gold standard method for diagnosis and treatment of choledocholithiasis. However, as indiscriminate use of ERCP increases the risk of procedure-related complications [2], ERCP is almost exclusively reserved for therapeutic purposes, and choledocholithiasis is usually diagnosed using non-invasive methods.

The benefits of using endoscopic ultrasonography (EUS) for the detection of CBD stones were described by Amouyal et al. in 1989 [3]. EUS is less invasive than ERCP, and has excellent sensitivity and specificity for the detection of CBD stones [4,5]. Considering the increasing availability of EUS in hospitals, and recent reports that EUS may have a higher diagnostic accuracy than magnetic resonance cholangiopancreatography for the detection of small CBD stones $(<5 \mathrm{~mm})$, EUS should be recommended for the detection of CBD stones instead of ERCP, to minimize the risk of procedure-related complications. According to the 2010 American Society for Gastrointestinal Endoscopy (ASGE) guidelines [6], which mainly cite the studies by Bakun et al. and Abboud et al. $[7,8]$, an EUS-guided management algorithm may be cost-effective for patients with an intermediate risk of choledocholithiasis, while an ERCP-guided approach may be more economic in patients with a high risk of choledocholithiasis. However, we experienced several patients at our institution who fulfilled the criteria for a high likelihood of choledocholithiasis and underwent ERCP, in whom no stones were detected. Ang et al. [9] reported that CBD stones were detected in only $29.6 \%$ of the 112 patients in their study who fulfilled the criteria for a high likelihood of CBD stones, which is lower than previously reported rates [9-13]. We postulate that discrepancies between the likelihood of choledocholithiasis and the detection of CBD stones on EUS may be related to the length of time between the initial clinical presentation and the EUS examination, and that ERCP may not always be more appropriate than EUS in patients who fulfill the criteria for a high likelihood of choledocholithiasis. The aims of this study were to determine the diagnostic yield and optimal timing of EUS in patients with an intermediate or high likelihood of choledocholithiasis requiring therapeutic ERCP, and to identify the factors associated with detection of CBD stones in our endoscopy clinics.

\section{Methods}

\section{Study population}

This study was approved by the institutional review board of Siriraj Hospital. Patients who presented with clinical manifestations suggestive of choledocholithiasis, who had inconclusive findings on initial imaging examinations and subsequently underwent EUS between June 2009 and January 2012, were included in the study. The medical records were retrospectively reviewed and the demographic data, clinical manifestations at presentation, blood test results, imaging examination findings, EUS and ERCP findings, and clinical manifestations during the follow-up period were recorded and analyzed.

Patients were included in the study if they had at least two of the following clinical manifestations of choledocholithiasis: right upper abdominal or epigastric pain, jaundice, fever, unexplained derangement of liver function tests, or abnormal findings on imaging examinations of the hepatobiliary tract such as a dilated CBD ( $\geq 7 \mathrm{~mm}$ with an intact gallbladder or $\geq 10 \mathrm{~mm}$ after cholecystectomy) or a suspected CBD stone. The exclusion criteria were: age $<18$ years, pregnancy, and inability to provide informed consent. The patients were divided into two groups based on based on the likelihood of choledocholithiasis according to the clinical predictors described by the ASGE guidelines: an intermediate likelihood group and a high likelihood group (Figure 1) [6].

\section{EUS examinations}

Patients underwent EUS using a GF-UE160 radial echoendoscope (Olympus Corporation, Tokyo, Japan). EUS was performed by a dedicated endoscopist who was

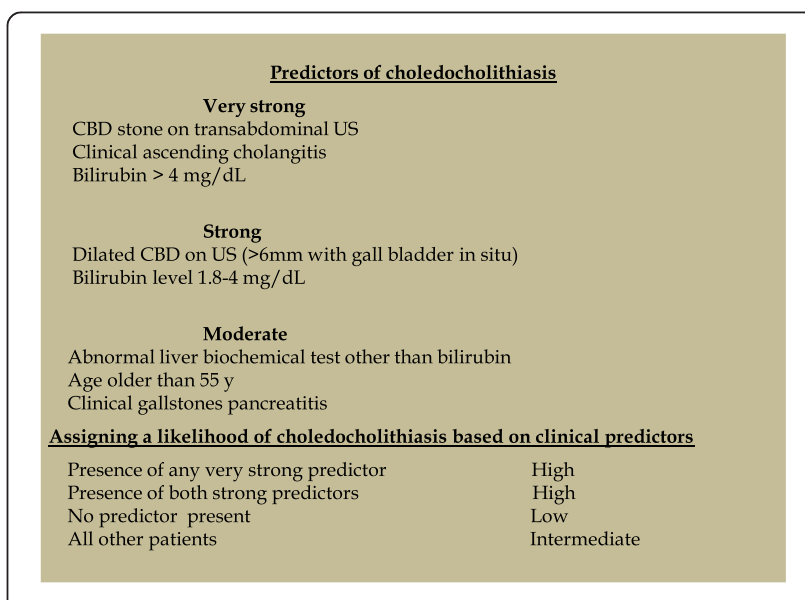

Figure 1 Clinical predictors of choledocholithiasis. CBD common bile duct, US ultrasonography. 
experienced in performing EUS at our university-based hospital, where more than 400 EUS procedures are performed annually. EUS was performed under conscious sedation administered by an anesthesiologist using midazolam, fentanyl, or propofol. The EUS findings were considered positive if hyperechoic foci were detected in the CBD, with or without associated acoustic shadows or biliary sludge. If the EUS findings were positive, patients underwent ERCP to remove the stones using a TJF-160VR duodenoscope (Olympus Corporation), by the same endoscopist as part of the same procedure. If EUS did not detect CBD stones, patients were followed up for at least 6 months after the index EUS procedure. If patients were lost to follow-up before the end of the 6-month follow-up period, their status was assessed by telephone. Four patients with negative EUS findings underwent ERCP because the consulting surgeon required a definitive diagnosis prior to performing laparoscopic cholecystectomy. Positive EUS findings were only considered truly positive if stones or sludge were visualized by ERCP. Patients with truly positive findings underwent sphincterotomy followed by basket or balloon sweeping of the bile duct. Negative EUS findings were considered truly negative if no stones or sludge were found during ERCP with balloon sweeping of the bile duct. A negative outcome associated with an EUSbased false-negative diagnosis was defined as detection of $\mathrm{CBD}$ stones during the follow-up period associated with pain thought to be of biliary origin, cholangitis, or acute pancreatitis. Clinical, blood test, and endoscopic findings were compared between patients with and without detection of CBD stones.

\section{Statistical analysis}

Descriptive data are presented as mean and standard deviation (SD). Factors associated with $\mathrm{CBD}$ stones were assessed by univariate analyses using the $\chi^{2}$-test, and by multivariate logistic regression analysis with calculation of odds ratios and 95\% confidence intervals (CIs). The sensitivity, specificity, negative predictive value, and positive predictive value of EUS for detection of CBD stones were calculated, using the ERCP findings as the gold standard. All statistical analyses were performed using SPSS software version 18.0.

\section{Results}

Ninety-three patients were included in the study, out of a total of 914 patients who underwent ERCP for CBD stone removal between June 2009 and January 2012. The mean $( \pm \mathrm{SD})$ age of the patients was $61.0( \pm 15.6)$ years (range, 26-85 years), and 47 (50.5\%) were men. The mean $( \pm \mathrm{SD})$ time between the initial clinical presentation and the EUS examination was $37.6( \pm 56.6)$ days (range, 1-420 days). The most common clinical manifestations were abdominal pain, jaundice, and fever, which occurred in $74.2 \%, 29.0 \%$, and $23.7 \%$ of patients, respectively. Leukocytosis was found in $25.8 \%$ of patients. The bilirubin level was abnormal in $53.2 \%$ of patients, and the mean $( \pm \mathrm{SD})$ total bilirubin level was $2.9( \pm 4.4) \mathrm{mg} / \mathrm{dL}$ (range, $0.2-34.8 \mathrm{mg} / \mathrm{dL}$ ). Abnormal liver enzyme levels were found in $71.2 \%$ of patients. The mean $( \pm \mathrm{SD})$ serum glutamic-oxaloacetic transaminase level was 169.9 $( \pm 206.9) \mathrm{U} / \mathrm{L}$ (range, $10-936 \mathrm{U} / \mathrm{L})$, the mean $( \pm \mathrm{SD})$ serum glutamic-pyruvic transaminase level was $158.3( \pm 203.2)$ $\mathrm{U} / \mathrm{L}$ (range, 7-1376 U/L), and the mean $( \pm \mathrm{SD})$ alkaline phosphatase level was $174.3( \pm 156.4) \mathrm{U} / \mathrm{mL}$ (range, 36$885 \mathrm{U} / \mathrm{mL}$ ). According to the clinical classification criteria described previously [6], 52.7\% of the patients had an intermediate likelihood of choledocholithiasis and 47.3\% had a high likelihood choledocholithiasis.

EUS found CBD stones in 29 of the 93 patients (31.2\%). Thirty-three patients underwent ERCP on the same day as their EUS examination, including 29 with CBD stones detected on EUS (28 truly positive) and 4 without CBD stones detected on EUS (all truly negative). EUS therefore had a sensitivity of $100 \%$ and specificity of $80 \%$ for detection of CBD stones, with a positive predictive value of $96.55 \%$ and a negative predictive value of $100 \%$. Patients who did not have CBD stones detected on EUS were followed up. The mean $( \pm \mathrm{SD})$ follow-up period was 10.2 ( \pm 7.9$)$ months (range, 1-41 months). Thirty-four patients (36.6\%) were lost to follow-up within 6 months. All the patients lost to follow-up were contacted by telephone, and none of them experienced any abdominal pain suspicious of biliary colic or underwent ERCP for stone removal at another hospital.

Table 1 shows the EUS and ERCP findings. CBD stones were detected in $22.44 \%$ of patients with an intermediate likelihood of choledocholithiasis and $38.63 \%$ of patients with a high likelihood of choledocholithiasis.

Univariate analyses of the factors potentially associated with choledocholithiasis are shown in Table 2. An elevated alkaline phosphatase level and EUS examination within 7 days of the initial clinical presentation were associated with detection of CBD stones.

Subgroup analysis was performed to compare patients who underwent EUS within 7 days of the initial clinical presentation and patients who underwent EUS more than 7 days after the initial clinical presentation. An

\section{Table 1 Detection of CBD stones by EUS and ERCP}

\begin{tabular}{lll}
\hline & $\begin{array}{l}\text { CBD stone detected } \\
\text { by EUS } \mathbf{n}(\%)\end{array}$ & $\begin{array}{l}\text { CBD stone detected } \\
\text { by ERCP } \mathbf{n}(\%)\end{array}$ \\
\hline $\begin{array}{l}\text { Intermediate likelihood } \\
(\mathrm{n}=49)\end{array}$ & $11(22.44 \%)$ & $11(22.44 \%)$ \\
High likelihood $(\mathrm{n}=44)$ & $18(40.90 \%)$ & $17(38.63 \%)$ \\
\hline
\end{tabular}

$C B D$ common bile duct, EUS endoscopic ultrasonography, ERCP endoscopic retrograde cholangiopancreatography. 
Table 2 Univariate analyses of factors potentially associated with detection of CBD stones

\begin{tabular}{|c|c|c|c|}
\hline & No CBD stone detected $(n=65)$ & CBD stone detected $(n=28)$ & $p$ value \\
\hline Mean $( \pm S D)$ age (years) & $58.85( \pm 16.09)$ & $65.26( \pm 13.76)$ & 0.06 \\
\hline Mean $( \pm \mathrm{SD})$ alkaline phosphatase level $(\mathrm{U} / \mathrm{mL})$ & $147.40( \pm 127.55)$ & $226.30( \pm 192.64)$ & $0.02^{*}$ \\
\hline Mean $( \pm \mathrm{SD})$ total bilirubin level (mg/dL) & $3.19( \pm 5.20)$ & $2.57( \pm 2.33)$ & 0.54 \\
\hline Mean $( \pm S D)$ SGOT level $(U / L)$ & $215.13( \pm 176.86)$ & $215.13( \pm 250.75)$ & 0.13 \\
\hline Mean ( \pm SD) SGPT level (U/L) & $137.07( \pm 210.94)$ & $198.65( \pm 184.04)$ & 0.17 \\
\hline Clinical classification & & & 0.06 \\
\hline Intermediate likelihood $(n=49)$ & 38 & 11 & \\
\hline High likelihood ( $n=44)$ & 27 & 17 & \\
\hline \multicolumn{4}{|l|}{ Dilated CBD on transabdominal } \\
\hline ultrasonography $(n=26)$ & 5 & 21 & 0.48 \\
\hline Mean $( \pm S D)$ time interval (days) & $38.95( \pm 62.77)$ & $33.23( \pm 42.24)$ & 0.64 \\
\hline EUS performed within 7 days (n) & 14 & 14 & $0.02 *$ \\
\hline
\end{tabular}

CBD common bile duct, EUS endoscopic ultrasonography, ERCP endoscopic retrograde cholangiopancreatography, SGOT serum glutamic-oxaloacetic transaminase, SGPT serum glutamic-pyruvic transaminase.

alkaline phosphatase level of $>133 \mathrm{mg} / \mathrm{dL}$ (area under the curve, 0.576) was the only factor associated with detection of CBD stones in patients who underwent EUS more than 7 days after the initial clinical presentation (odds ratio: 4.87, $p=0.01$ ) (Table 3 ). Additional analyses of individual or combined choledocholithiasis predictors that are classified as "strong" or "very strong" in the ASGE guidelines [6] did not show significant associations between these factors and the detection of CBD stones (data not shown).

\section{Discussion}

The reported sensitivity and specificity of non-invasive imaging examinations for the detection of CBD stones are $25-58 \%$ and $68-91 \%$, respectively, for transabdominal ultrasonography; and 87\% (95\% CI: 84-90) and 97\% (95\% CI: 95-98), respectively, for computed tomography [14]. Magnetic resonance cholangiopancreatography has a sensitivity of approximately 91\% (95\% CI: 73-97) for detection of CBD stones, depending on the stone size as follows: $67-100 \%$ for stones $>10 \mathrm{~mm}, 89-94 \%$ for stones $6-10 \mathrm{~mm}$, and $33-71 \%$ for stones $<6 \mathrm{~mm}$ [14]. The optimal initial non-operative investigation for the detection of CBD stones is therefore still unclear.

Although ERCP is the gold standard method for detection of $\mathrm{CBD}$ stones, with a reported sensitivity of $90 \%$ and specificity of $98 \%$, indiscriminate use of ERCP results in an increased rate of associated complications. ERCP is therefore almost exclusively used for therapeutic purposes, with non-invasive tests used for the detection of CBD stones. EUS is a new, less invasive imaging technique that has shown very good sensitivity (95\%) and specificity (98\%) for the detection of CBD stones $[4,5]$. In this study, EUS detected CBD stones in all the patients who were truly positive for CBD stones, with only one false-positive case. Retrospective review of the EUS images from the false-positive case showed a suspected echo artifact. EUS should be the imaging examination of choice for the detection of CBD stones, because of its high sensitivity and specificity. EUS is as effective as ERCP for detecting CBD stones, and has fewer procedural risks and complications. However, EUS also has some disadvantages, including the high cost, the need for expertise in the procedure, and the lack of availability in some hospitals.

The present study included almost equal numbers of patients with intermediate and high likelihood of choledocholithiasis. CBD stones were detected in $22.44 \%$ of patients in the intermediate likelihood group and $38.63 \%$ of patients in the high likelihood group. These results differ from previous studies, which reported detection of CBD stones in up to $40 \%$ of patients in the intermediate likelihood group and $60 \%$ of patients in the high likelihood group [10-15]. We postulate that the lower rate

Table 3 Detection of CBD stones in patients with an alkaline phosphatase level $>133 \mathrm{mg} / \mathrm{dL}$, who underwent EUS $\leq 7$ days and $>7$ days after the initial clinical presentation

\begin{tabular}{|c|c|c|c|}
\hline & $\begin{array}{l}\text { No CBD stone } \\
\text { detected }(n=65)\end{array}$ & $\begin{array}{l}\text { CBD stone } \\
\text { detected }(n=28)\end{array}$ & $p$ value \\
\hline Alkaline phosphatase level >133 mg/dL and EUS $\leq 7$ days after presentation $(n=17)$ & 7 & 10 & 0.29 \\
\hline Alkaline phosphatase level $>133 \mathrm{mg} / \mathrm{dL}$ and EUS $>7$ days after presentation $(n=25)$ & 14 & 11 & $0.01^{*}$ \\
\hline
\end{tabular}


detection of CBD stones in our study may reflect spontaneous passage of the stones, which is reported to occur at a rate of $20 \%$ per week [16], and would be affected by the time between the initial clinical presentation and the EUS examination. Our findings therefore support the potential cost-effectiveness of EUS for patients with an intermediate likelihood of choledocholithiasis suggested by the ASGE algorithm, and the performance of EUSguided ERCP. However, routine ERCP may not be appropriate for all patients with a high likelihood of choledocholithiasis.

In the past decade, many studies have demonstrated that EUS is as accurate as ERCP for the detection of CBD stones, and that EUS is associated with fewer complications than ERCP [17-22]. However, EUS is not available in all hospitals, especially in developing countries. Currently, EUS is only available in large tertiary hospitals, which may result in delay between the initial clinical presentation and the EUS examination. In the current study, patients who underwent EUS within 7 days of the initial presentation were more likely to have positive findings than patients who underwent EUS more than 7 days after the initial clinical presentation. Our analyses show that EUS more than 7 days after the initial clinical presentation and an elevated alkaline phosphatase level were associated with detection of CBD stones, especially when the alkaline phosphatase level was $>133 \mathrm{mg} / \mathrm{dL}$.

This study was limited by its retrospective design and the relatively small number of patients. The results are therefore only applicable to similar healthcare situations. Further prospective studies should be conducted to confirm the findings of this study.

\section{Conclusions}

EUS is an accurate diagnostic tool for the detection of CBD stones, and can reduce the unnecessary use of ERCP. This study demonstrated that use of clinical criteria alone might not provide good predictions regarding the presence of CBD stones in all patients, even those who fulfill the criteria for a high likelihood of choledocholithiasis. EUS examination should be considered for patients with a high likelihood of choledocholithiasis, especially those who cannot undergo ERCP within 7 days of the initial clinical presentation or who have a high risk of ERCP-related complications, to minimize unnecessary ERCP procedures.

\section{Abbreviations}

ASGE: American society for gastrointestinal endoscopy; CBD: Common bile duct; Cl: Confidence interval; ERCP: Endoscopic retrograde cholangiopancreatography; EUS: Endoscopic ultrasonography; SD: Standard deviation.

\section{Competing interests}

The authors declare that they have no competing interest.

\section{Authors' contributions}

VP conceived and designed the study. PB, MD and AP acquired the data. VP and PA wrote and revised the paper and incorporated important intellectual content. All authors read and proved the final manuscript.

\section{Acknowledgments}

We are grateful to Dr Nonthalee Pausawasdi and Dr Supot Pongprasobchai for allowing inclusion of their patients in the study.

\section{Funding}

No funding was received for this study.

\section{Author details}

'Department of Internal Medicine, Siriraj Gl Endoscopy Center, Siriraj Hospital, Division of Gastroenterology, Faculty of Medicine, Mahidol University, Bangkok, Thailand. 'Liver and Digestive Institute, Samitivej Sukhumvit Hospital, Bangkok, Thailand. ${ }^{3}$ Department of Medicine, Patommatat Bhunthumkomol, Gastrointestinal Unit, Thammasat University Hospital, Pathumthani 12120, Thailand.

Received: 17 April 2014 Accepted: 24 September 2014

Published: 26 September 2014

\section{References}

1. Freitas ML, Bell RL, Duffy AJ: Choledocholithiasis: evolving standards for diagnosis and management. World J Gastroenterol 2006, 12:3162-3167.

2. Petrov MS, Savides TJ: Systematic review of endoscopic ultrasonography versus endoscopic retrograde cholangiopancreatography for suspected choledocholithiasis. Br J Surg 2009, 96:967-974.

3. Amouyal P, Palazzo L, Amouyal G, Ponsot P, Mompoint D, Vilgrain V, Gayet B, Fléjou JF, Paolaggi JA: Endosonography: promising method for diagnosis of extrahepatic cholestasis. Lancet 1989, 2:1195-1195.

4. Garrow D, Miller S, Sinha D, Conway J, Hoffman BJ, Hawes RH, Romagnuolo $\mathrm{J}$ : Endoscopic ultrasound: a meta-analysis of test performance in suspected biliary obstruction. Clin Gastroenterol Hepatol 2007, 5:616-623.

5. Tse F, Liu L, Barkun AN, Armstrong D, Moayyedi P: EUS: a meta-analysis of test performance in suspected choledocholithiasis. Gastrointest Endosc 2008, 67:235-244

6. ASGE Standards of Practice Committee, Maple JT, Ben-Menachem T, Anderson MA, Appalaneni V, Banerjee S, Cash BD, Fisher L, Harrison ME, Fanelli RD, Fukami N, Ikenberry SO, Jain R, Khan K, Krinsky ML, Strohmeyer L, Dominitz JA: The role of endoscopy in the evaluation of suspected choledocholithiasis. Gastrointest Endosc 2010, 71:1-9.

7. Barkun AN, Barkun JS, Fried GM, Ghitulescu G, Steinmetz O, Pham C, Meakins $\lrcorner$, Goresky CA: Useful predictors of bile duct stones in patients undergoing laparoscopic cholecystectomy. McGill Gallstone Treatment Group. Ann Surg 1994, 220:32-39.

8. Abboud PAC, Malet PF, Berlin JA, Staroscik R, Cabana MD, Clarke JR, Shea JA, Schwartz JS, Williams SV: Predictors of common bile duct stones prior to cholecystectomy: a meta-analysis. Gastrointest EndosC 1996, 44:450-455.

9. Ang TL, Liew SFAP, Ang D, Kwek A, Fock KM, Teo EK: EUS-guided ERCP in patients with negative cross sectional imaging but high clinical probability of choledocholithiasis. Gastrointest Endosc 2012, 75:AB203.

10. Polkowski M, Regula J, Tilszer A, Butruk E: Endoscopic ultrasound versus endoscopic retrograde cholangiography for patients with intermediate probability of bile duct stones: a randomized trial comparing two management strategies. Endoscopy 2007, 39:296-303.

11. Lee YT, Chan FKL, Leung WK, Chan HL, Wu JC, Yung MY, Ng EK, Lau JY, Sung JJ: Comparison of EUS and ERCP in the investigation with suspected biliary obstruction caused by choledocholithiasis: a randomized study. Gastrointest Endosc 2008, 67:660-668.

12. Karakan $T$, Cindoruk M, Alagozlu H, Ergun M, Dumlu S, Unal S: EUS versus endoscopic retrograde cholangiography for patients with intermediate probability of bile duct stones: a prospective randomized trial. Gastrointest Endosc 2009, 69:244-252.

13. Benjaminov F, Stein A, Lichtman G, Pomeranz I, Konikoff FM: Consecutive versus separate session of endoscopic ultrasound (EUS) and endoscopic retrograde cholangiopancreatography (ERCP) for symptomatic choledocholithiasis. Surg Endosc 2013, 27:2117-2121. 
14. Tse F, Barkun JS, Romagnuolo J, Friedman G, Bornstein JD, Barkun AN: Nonoperative imaging techniques in suspected biliary tract obstruction. HPB (Oxford) 2006, 8:409-425.

15. Malik S, Kaushik N, Khalid A, Bauer K, Brody D, Slivka A, McGrath K: EUS yield in evaluating biliary dilatation in patients with normal serum liver enzymes. Dig Dis Sci 2007, 52:508-512.

16. Frossard JL, Hadengue A, Amouyal G, Choury A, Marty O, Giostra E, Sivignon F, Sosa L, Amouyal P: Choledocholithiasis: a prospective study of spontaneous common bile duct stone migration. Gastrointest Endosc 2000, 51:175-179.

17. Lisi SD, Leandro G, Buscarini E: Endoscopic ultrasonography versus endoscopic retrograde cholangiopancreatography in acute biliary pancreatitis: a systematic review. Eur I Gastroenterol Hepatol 2011, 23:367-374

18. Napoléon B, Dumortier J, Keriven-Souquet O, Pujol B, Ponchon T, Souquet JC: Do normal finding at biliary endoscopic ultrasonography obviate the need for endoscopic retrograde cholangiography in patients with suspicion of common bile duct stone? A prospective follow-up study of 238 patients. Endoscopy 2003, 35:411-415.

19. Chan HH, Wang EM, Sun MS, Hsu PI, Tsai WL, Tsai TJ, Wang KM, Chen WC, Liang HL, Lai KH, Brugge WR: Linear echoscope-guided ERCP for the diagnosis of occult common bile duct stones. BMC Gastroenterol 2013, 13:13-44.

20. Caerriere V, Conway J, Evans J, Shokoohi S, Mishra G: Which patients with dilated common bile and/or pancreatic ducts have positive findings on EUS? J Interv Gastroenterol 2012, 2:168-171.

21. Cui ML, Cho JH, Kim TN: Long-term follow-up study of gallbladder in situ after endoscopic common duct stone removal in Korean patients. Surg Endosc 2013, 27:1711-1716.

22. da Silveira EB, Barkun AN: EUS-first versus ERC-first for patients with intermediate probability of bile duct stones: is one strategy superior to the other? Endoscopy 2007, 39:357-358

doi:10.1186/1471-230X-14-165

Cite this article as: Prachayakul et al: Diagnostic yield of endoscopic ultrasonography in patients with intermediate or high likelihood of choledocholithiasis: a retrospective study from one university-based endoscopy center. BMC Gastroenterology 2014 14:165.

\section{Submit your next manuscript to BioMed Central and take full advantage of:}

- Convenient online submission

- Thorough peer review

- No space constraints or color figure charges

- Immediate publication on acceptance

- Inclusion in PubMed, CAS, Scopus and Google Scholar

- Research which is freely available for redistribution 